\title{
Preventive effects of chrysin on the development of azoxymethane-induced colonic aberrant crypt foci in rats
}

\author{
SHINGO MIYAMOTO ${ }^{1}$, HIROYUKI KOHNO ${ }^{2}$, RIKAKO SUZUKI ${ }^{2}$, \\ SHIGEYUKI SUGIE ${ }^{2}$, AKIRA MURAKAMI ${ }^{1}$, HAJIME OHIGASHI $^{1}$ and TAKUJI TANAKA ${ }^{2}$ \\ ${ }^{1}$ Division of Food Science and Biotechnology, Graduate School of Agriculture, Kyoto University, Kyoto 606-8502; \\ ${ }^{2}$ Department of Oncologic Pathology, Kanazawa Medical University, 1-1 Daigaku, Uchinada, Ishikawa 920-0293, Japan
}

Received October 4, 2005; Accepted December 2, 2005

\begin{abstract}
The modifying effects of dietary feeding with chrysin (5,7-dihydroxyflavone) on the development of azoxymethane (AOM)-induced colonic aberrant crypt foci (ACF) were investigated in male F344 rats. We also assessed the effect of chrysin on mitosis and apoptosis in "normal appearing' crypts. To induce ACF, rats were given two weekly subcutaneous injections of AOM $(20 \mathrm{mg} / \mathrm{kg}$ body weight). They also received an experimental diet containing chrysin $(0.001$ or $0.01 \%)$ for 4 weeks, starting 1 week before the first dose of AOM. AOM exposure produced a substantial number of ACF (73 $\pm 13 /$ rat) at the end of the study (week 4). Dietary administration of chrysin caused significant reduction in the frequency of ACF: $0.001 \%$ chrysin, $37 \pm 17 /$ rat $(49 \%$ reduction, $\mathrm{P}<0.001)$; and $0.01 \%$ chrysin, $40 \pm 10 /$ rat $(45 \%$ reduction, $\mathrm{P}<0.001)$. In addition, chrysin administration significantly reduced the mitotic index and significantly increased the apoptotic index in 'normal appearing' crypts. These findings might suggest a possible chemopreventive activity of chrysin in the early step of colon tumorigenesis through modulation of cryptal cell proliferation activity and apoptosis.
\end{abstract}

\section{Introduction}

Colorectal cancer is one of the leading causes of cancer death in Western countries. Globally, colorectal cancer accounted for approximately 1 million new cases in 2002 (9.4\% of the world) and mortality is approximately one half that of incidence ( 529,000 deaths in 2002) (1). In Japan, its incidence has been increasing and colonic malignancy is now the third leading cause of cancer death. In this context, primary prevention,

Correspondence to: Dr Shingo Miyamoto, Division of Food Science and Biotechnology, Graduate School of Agriculture, Kyoto University, Kyoto 606-8502, Japan

E-mail: shingo7@kanazawa-med.ac.jp

Key words: chrysin, aberrant crypt foci, mitosis, apoptosis including chemoprevention, is important for fighting this malignancy.

Flavonoids are plant secondary metabolites ubiquitously distributed throughout the plant kingdom, and numerous reports have shown their biological effects, such as antioxidative and anti-inflammatory activity. They also act as inhibitors of several enzymes that are activated in certain inflammatory conditions (2), while a variety of cell types associated with the immune system are down-regulated by certain flavonoids in vitro (3). Further, most flavonoids show potent anti-oxidative/radical scavenging effects (4). A natural flavonoid, chrysin (5,7-dihydroxyflavone, Fig. 1), which is a potent inhibitor of the enzyme, CYP1A (5), and aromatase (6), is present in many plants, honey, and propolis $(7,8)$. Studies have shown that chrysin suppresses lipopolysaccharide (LPS)-induced cyclooxygenase (COX)-2 and inducible nitric oxide synthase (iNOS) expression through the activation of peroxisome proliferator-activated receptor (PPAR)- $\gamma$ (9). In our previous studies, a polymethoxy flavonoid, nobiletin (5,6,7,8,3', '4'-hexamethoxyflavone), suppressed the expression of proinflammatory genes, such as iNOS and COX-2, in vitro (10) and inhibited azoxymethane (AOM)-induced rat colon carcinogenesis (11). In addition, pomegranate (Punica granatum L.) seed oil, which contains more than $70 \%$ conjugated linolenic acids, in the diet suppressed AOMinduced colon carcinogenesis in rats through an up-regulation of PPAR $\gamma$ protein in the non-tumorous colonic mucosa (12). Thus, proinflammatory genes and PPAR $\gamma$ are good targets for chemoprevention of colon carcinogenesis.

Recently, several in vitro studies have shown that chrysin is able to inhibit the growth of Hela cells by downregulating the expression of proliferating cell nuclear antigen (PCNA) (13), induce apoptosis via caspase activation and Akt inactivation in U937 leukemia cells (14), and cause cell-cycle arrest in human colon cancer cells (15), and C6 glioma cells (16). However, there are few reports investigating whether chrysin has cancer chemopreventive effects on the colon in experimental animal studies.

In the current study, we investigated the possible suppressing effect of chrysin on the occurrence of AOMinduced aberrant crypt foci (ACF), which are putative preneoplastic lesions for colonic adenocarcinoma (17-19), with a short-term rat ACF bioassay. In addition, we assess 


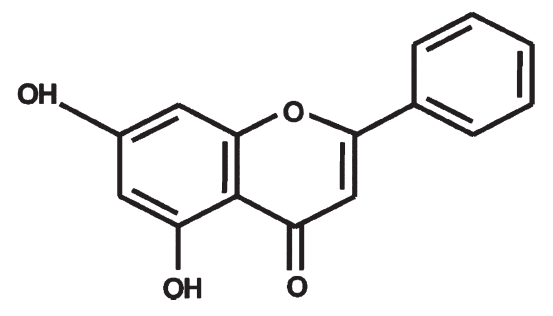

Figure 1. Chemical structure of chrysin.

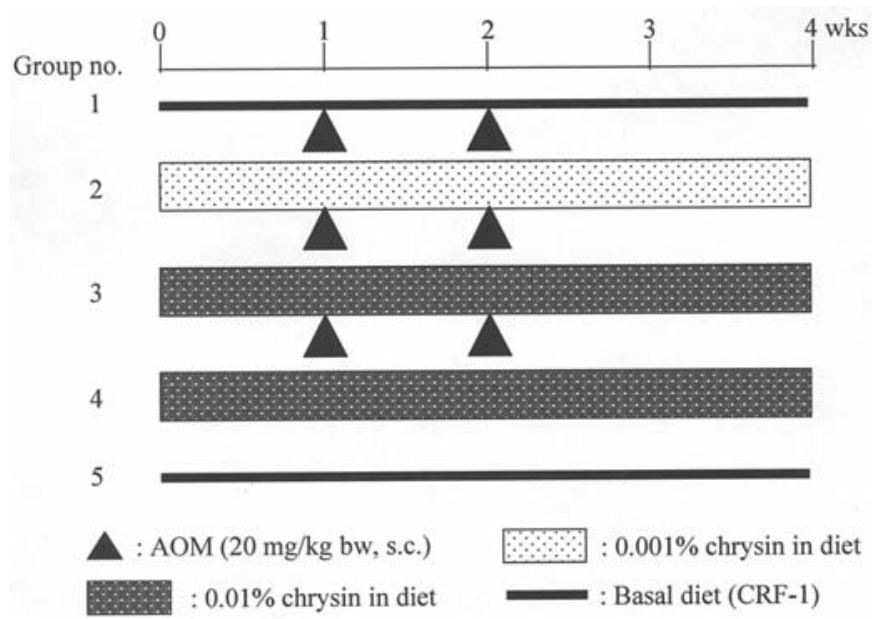

Figure 2. Experimental protocol.

whether dietary chrysin affects cell proliferation activity and induces apoptosis in the colonic epithelium, since certain chemopreventive agents exert cancer inhibitory action through reduction of cell proliferating activity (20) and induction of apoptosis (21) in the target tissue.

\section{Materials and methods}

Animals, chemicals and diet. Male F344 rats (Charles River Japan, Inc, Kanazawa, Japan), aged 4 weeks, were used for an ACF assay. The animals were maintained in Kanazawa Medical University Animal Facility according to the Institutional Animal Care Guidelines. All animals were housed in plastic cages (4 rats/cage) with free access to tap water and a basal MF diet (Oriental Yeast, Co., Ltd., Nagoya, Japan) under controlled conditions of humidity $(50 \pm 10 \%)$, lighting (12-h light/dark cycle), and temperature $\left(23 \pm 2^{\circ} \mathrm{C}\right)$. They were quarantined for 7 days after arrival, and randomized by body weight into experimental and control groups. AOM for ACF induction was purchased from Sigma-Aldrich Chemical Co. (St. Louis, MO, USA). Chrysin was obtained from Funakoshi Co. (Tokyo, Japan).

Experimental procedure for ACF. A total of 32 male F344 rats were divided into five experimental and control groups (Fig. 2). Animals in groups 1 through 3 were initiated with AOM by two weekly subcutaneous injections $(20 \mathrm{mg} / \mathrm{kg}$ body weight) to induce colonic ACF. Rats in groups 2 and 3 were fed diets containing $0.001 \%$ and $0.01 \%$ chrysin for 4 weeks, respectively, starting one week before the first dose of

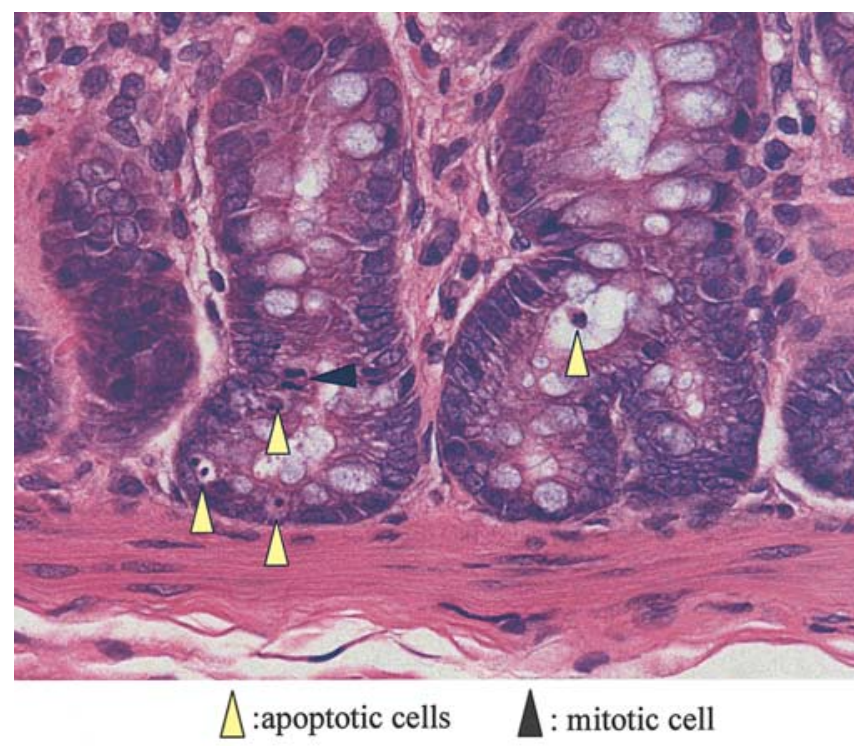

Figure 3. Apoptotic and mitotic cells in the crypt from the distal colon, which was stained with hematoxylin and eosin, from a rat in group 3 (AOM+0.01\% chrysin). Apoptotic cells are identified by cell shrinkage, homogeneous basophilic and condensed nuclei, nuclear fragments (apoptotic bodies), marked eosinophilic condensation of cytoplasm and sharply delineated cell borders surrounded by a clear halo. Yellow arrowheads indicate apoptotic cells and the black arrowhead indicates a mitotic cell.

AOM. Group 4 did not receive AOM and were given the diet containing $0.01 \%$ chrysin. Group 5 served as an untreated control. At week 4, rats were sacrificed under ether anesthesia to assess the occurrence of colonic ACF and we performed a careful necropsy, with emphasis on the colon, liver, kidney, lung, and heart. All grossly abnormal lesions in any tissue and the organs, e.g. liver (caudate lobe), kidney, lung, and heart, were fixed in $10 \%$ buffered formalin solution for histopathology.

Determination of ACF. The frequency of ACF was determined according to the method described in our previous report (22). At necropsy, the colons were flushed with saline, excised, cut open longitudinally along the main axis, and then washed with saline. They were cut and fixed in $10 \%$ buffered formalin for at least $24 \mathrm{~h}$. The fixed colons were dipped in a $0.5 \%$ solution of methylene blue in distilled water for $30 \mathrm{sec}$, and placed on a microscope slide to count the ACF.

Counting mitotic and apoptotic cells. To identify intramucosal apoptotic and mitotic cells in the crypts, the distal colon $(2 \mathrm{~cm}$ from the anus) was cut out, embedded in paraffin, and $4 \mu \mathrm{m}$ thick serial sections were made. The paraffin-embedded sections were stained with hematoxylin and eosin (H\&E) and evaluated under a light microscope for apoptotic and mitotic cells at a magnification of 400 (Fig. 3). Apoptotic cells were identified by cell shrinkage, homogeneous basophilic and condensed nuclei, nuclear fragments (apoptotic bodies), marked eosinophilic condensation of the cytoplasm, and sharply delineated cell borders surrounded by a clear halo (23). The apoptotic and mitotic indices in the colonic crypts were determined on longitudinal sections that allowed evaluation of the whole crypt from the top to the base. 
Table I. Body, liver, and relative liver weights.

\begin{tabular}{lcccc}
\hline Group no. & $\begin{array}{c}\text { Treatment } \\
\text { (no. of rats examined) }\end{array}$ & $\begin{array}{c}\text { Body weight } \\
(\mathrm{g})\end{array}$ & $\begin{array}{c}\text { Liver weight } \\
(\mathrm{g})\end{array}$ & $\begin{array}{r}\text { Relative liver weight } \\
(\mathrm{g} / 100 \mathrm{~g} \text { body weight })\end{array}$ \\
\hline 1 & AOM alone (8) & $194 \pm 8^{\mathrm{a}}$ & $9.7 \pm 0.7$ & $5.00 \pm 0.68$ \\
2 & AOM+0.001\% chrysin (8) & $192 \pm 7$ & $10.5 \pm 1.1$ & $5.47 \pm 0.45$ \\
3 & AOM+0.01\% chrysin (8) & $195 \pm 5$ & $9.9 \pm 0.5$ & $5.10 \pm 0.18$ \\
4 & $0.01 \%$ chrysin (4) & $203 \pm 7$ & $10.5 \pm 0.9$ & $5.14 \pm 0.28$ \\
5 & No treatment (4) & $196 \pm 9$ & $9.4 \pm 0.5$ & $4.80 \pm 0.17$ \\
\hline
\end{tabular}

${ }^{\mathrm{a}}$ Mean \pm SD.

Table II. Effect of chrysin on AOM-induced ACF formation in male F344 rats.

\begin{tabular}{lccccc}
\hline Group no. & $\begin{array}{c}\text { Treatment } \\
\text { (no. of rats examined) }\end{array}$ & $\begin{array}{c}\text { Incidence } \\
(\%)\end{array}$ & $\begin{array}{c}\text { Total no. of } \\
\text { ACF/colon }\end{array}$ & $\begin{array}{c}\text { Total no. of aberrant } \\
\text { crypts/colon }\end{array}$ & $\begin{array}{c}\text { No. of aberrant } \\
\text { crypts/focus }\end{array}$ \\
\hline 1 & AOM alone (8) & $8 / 8(100 \%)$ & $73 \pm 13^{\mathrm{a}}$ & $145 \pm 28$ & $1.98 \pm 0.10$ \\
2 & AOM+0.001\% chrysin (8) & $8 / 8(100 \%)$ & $37 \pm 17^{\mathrm{b}}$ & $67 \pm 29^{\mathrm{b}}$ & $1.81 \pm 0.14^{\mathrm{c}}$ \\
3 & AOM+0.01\% chrysin (8) & $8 / 8(100 \%)$ & $40 \pm 10^{\mathrm{b}}$ & $69 \pm 21^{\mathrm{b}}$ & $1.73 \pm 0.09^{\mathrm{b}}$ \\
4 & $0.01 \%$ chrysin (4) & $0 / 4(0 \%)$ & 0 & 0 & 0 \\
5 & No treatment (4) & $0 / 4(0 \%)$ & 0 & 0 & 0
\end{tabular}

${ }^{\mathrm{a}}$ Mean $\pm \mathrm{SD}$, ${ }^{\mathrm{b}}$ significantly different from group 1 by one-way ANOVA with Bonferroni correction $(\mathrm{P}<0.001)$, ${ }^{\text {csignificantly different from }}$ group 1 by one-way ANOVA with Bonferroni correction $(\mathrm{P}<0.05)$.

Table III. Effect of chrysin on size of ACF induced by AOM.

\begin{tabular}{|c|c|c|c|c|c|}
\hline \multirow[t]{2}{*}{ Group no. } & \multirow{2}{*}{$\begin{array}{c}\text { Treatment } \\
\text { (no. of rats examined) }\end{array}$} & \multicolumn{4}{|c|}{$\%$ of ACF containing: } \\
\hline & & 1 crypt & 2 crypts & 3 crypts & $\geq 4$ crypts \\
\hline 1 & AOM alone (8) & $43.1 \pm 4.7^{\mathrm{a}}$ & $27.9 \pm 5.9$ & $19.1 \pm 5.2$ & $9.9 \pm 2.7$ \\
\hline 2 & $\mathrm{AOM}+0.001 \%$ chrysin $(8)$ & $44.2 \pm 3.8$ & $38.4 \pm 4.7^{b}$ & $0.3 \pm 4.1^{\mathrm{b}}$ & $7.1 \pm 6.1$ \\
\hline 3 & $\mathrm{AOM}+0.01 \%$ chrysin $(8)$ & $47.3 \pm 5.5$ & $34.4 \pm 6.4$ & $16.3 \pm 3.9^{c}$ & $2.0 \pm 3.1^{\mathrm{b}}$ \\
\hline
\end{tabular}

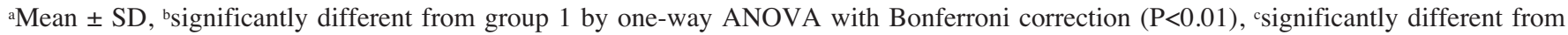
group 2 by one-way ANOVA with Bonferroni correction $(\mathrm{P}<0.05)$.

Randomly chosen crypts (28-57 crypts/colon) with welloriented crypt structure from the mouth to the base were evaluated for counting apoptosis and mitosis. The apoptotic and mitotic indices were determined by dividing the total number of apoptotic or mitotic cells by the number of epithelial cells evaluated.

Statistical evaluation. Where applicable, data were analyzed using one-way ANOVA with Bonferroni correction (GraphPad Instat version 3.05, GraphPad Softwear, San Diego, CA, USA) with $\mathrm{P}<0.05$ as the criterion of significance.

\section{Results}

General observation. All animals remained healthy throughout the experimental period. Food consumption (g/day/rat) did not differ significantly among the groups (data not shown). As shown in Table I, the mean body, liver and relative liver weights ( $\mathrm{g} / 100 \mathrm{~g}$ body weight) in all groups did not differ significantly at the end of the study. Further, no significant pathological alternations were found in organs other than the colon.

Frequency of $A C F$. Table II summarizes the data on colonic $\mathrm{ACF}$ formation. All rats belonging to groups 1 through 3, which were treated with AOM, developed ACF. In groups 4 and 5, there was no microscopically observable change, including $\mathrm{ACF}$, in colonic morphology. The mean number of $\mathrm{ACF} /$ colon in group 1 was $73 \pm 13$. Dietary administration of chrysin (groups 2 and 3) significantly reduced the ACF incidence when compared to group 1: $49 \%$ reduction by $0.001 \%$ chrysin (group 2), $\mathrm{P}<0.001$; and $45 \%$ reduction by 
Table IV. Epithelial proliferative kinetics in the distal colon.

\begin{tabular}{lcccc}
\hline Group no. & $\begin{array}{c}\text { Treatment } \\
\text { (no. of crypts examined) }\end{array}$ & $\begin{array}{c}\text { Mitotic index } \\
(\%)\end{array}$ & $\begin{array}{c}\text { Apoptotic index } \\
(\%)\end{array}$ & Crypt column height \\
\hline 1 & AOM alone (44) & $4.3 \pm 2.5^{\mathrm{a}, \mathrm{b}}$ & $1.2 \pm 1.6$ & $44.2 \pm 10.1^{\mathrm{b}}$ \\
2 & AOM+0.001\% chrysin (38) & $3.2 \pm 2.5$ & $3.2 \pm 2.3^{\mathrm{c}}$ & $43.3 \pm 6.9$ \\
3 & AOM+0.01\% chrysin (57) & $1.4 \pm 1.4^{\mathrm{c}}$ & $3.7 \pm 2.1^{\mathrm{c}}$ & $55.4 \pm 10.2^{\mathrm{c}}$ \\
4 & $0.01 \%$ chrysin (56) & $1.8 \pm 1.4$ & $1.2 \pm 1.2$ & $54.0 \pm 11.1^{\mathrm{d}}$ \\
5 & No treatment (28) & $1.3 \pm 1.4$ & $0.8 \pm 1.0$ & $62.0 \pm 11.7$ \\
\hline
\end{tabular}

${ }^{\mathrm{a}}$ Mean $\pm \mathrm{SD}$, ${ }^{\mathrm{b}}$ significantly different from group 5 by one-way ANOVA with Bonferroni correction $(\mathrm{P}<0.001)$, ${ }^{\mathrm{c}}$ significantly different from group 1 by one-way ANOVA with Bonferroni correction $(\mathrm{P}<0.001)$, ${ }^{\mathrm{d}}$ significantly different from group 5 by one-way ANOVA with Bonferroni correction $(\mathrm{P}<0.01)$

$0.01 \%$ chrysin (group 3), $\mathrm{P}<0.001$. In addition, there were significant decreases in the total number of aberrant crypts (ACs) per colon $(\mathrm{P}<0.001)$, and in the number of $\mathrm{ACs}$ per focus in group $2(9 \%$ reduction, $\mathrm{P}<0.05)$ and group $3(13 \%$ reduction, $\mathrm{P}<0.001$ ) when compared to group 1 . The size distribution of ACF induced by AOM in groups 1-3 showed in Table III. The percentages of ACF consisting of one crypt did not significantly differ among these three groups. Although the percentage of ACF with 2 crypts in group 2 was significantly greater than that in group $1(\mathrm{P}<0.01)$, the values of ACF with 3 crypts in groups 2 and 3 were significantly smaller than in group $1(\mathrm{P}<0.01$ and $\mathrm{P}<0.05$, respectively). As for the percentage of ACF with $\geq 4$ crypts, the value in group 3 was significantly lower than that in group $1(\mathrm{P}<0.01)$.

Indices of mitosis and apoptosis in colonic crypts. The data on the epithelial proliferative kinetics in 'normal appearing' distal colon are summarized in Table IV. The mitotic index was significantly higher in group $1(4.3 \pm 2.5,331 \%$ increase, $\mathrm{P}<0.001)$ than in group 5 . The dietary administration of chrysin (groups 2 and 3) reduced the mitotic index in a dosedependent manner when compared to group 1: $26 \%$ reduction by $0.001 \%$ chrysin (group 2); and $67 \%$ reduction by $0.01 \%$ chrysin, $\mathrm{P}<0.001$ (group 3). Feeding with $0.01 \%$ chrysin alone (group 4) did not affect the mitotic index in the crypts. The apoptotic indices of groups 1, 4 and 5 were comparable, but the values in groups 2 and 3 were significantly increased when compared to group $1(\mathrm{P}<0.001)$. As for the crypt column height (no. of cells/crypt), the value in group 1 was significantly smaller than in group $5(\mathrm{P}<0.001)$. The crypt column height of group 3 was significantly larger than that of group $1(\mathrm{P}<0.001)$. The value in group 4 was significantly lower than in group $5(\mathrm{P}<0.01)$.

\section{Discussion}

The results described here clearly indicate that dietary administration of chrysin at dose levels of $0.001 \%$ and $0.01 \%$ significantly inhibited AOM-induced ACF formation in male F344 rats. Moreover, the percentage of ACF that consisted of 4 or more aberrant crypts was significantly reduced by feeding with the diet supplemented with $0.01 \%$ chrysin. These findings indicate that dietary chrysin effectively suppresses the early phase of chemically-induced rat colon tumorigenesis. Also, the inhibitory effect of chrysin $(0.001 \%)$ in the diet on the formation of large ACF may suggest suppression of the late stage of AOM-induced colon carcinogenesis, since the number of large ACF is well correlated with the incidence of colonic adenocarcinoma induced by a colonic carcinogen, AOM $(18,19,24)$. Our results are the first to show the chemopreventive ability of chrysin in ACF formation in an in vivo study with a colon carcinogenesis model.

The oral disposition of the dietary flavonoid, chrysin, in humans has been reported (25). Seven healthy subjects were administered $400 \mathrm{mg}$ chrysin orally and the areas under the plasma concentration-time curves (AUCs) and urinary recoveries of chrysin and metabolites were measured. As a result, peak plasma chrysin concentrations were only 3-16 ng $\mathrm{ml}^{-1}$ with AUCs of 5-193 $\mathrm{ng} \mathrm{ml}^{-1} \mathrm{~h}$, whereas chrysin sulphate concentrations were 30 -fold higher (AUC $450-4220 \mathrm{ng} \mathrm{ml}^{-1} \mathrm{~h}$ ). In urine, chrysin and chrysin glucuronide accounted for $0.2-$ $3.1 \mathrm{mg}$ and 2-26 mg, respectively. Most of the dose appeared in faeces as unchanged chrysin. These findings, together with our data, might suggest that unchanged chrysin exists, not in plasma but in intestine, and directly affects the proliferation activity of cryptal cells.

Chrysin is a natural flavonoid that is contained in many plants, honey and propolis. Flavonoids are dietary polyphenols derived from fruits and vegetables (26). Epidemiological observations strongly suggest flavonoids to be preventive in coronary heart disease $(27,28)$, stroke $(29)$ and certain cancers (30). In this study, dietary administration of chrysin reduced the number of mitotic cells and increased the number of apoptotic cells. Recent studies have shown that chrysin induces apoptosis through caspase activation and Akt inactivation in U937 leukemia cells (14), and G2/M cell-cycle arrest in human colon carcinoma SW480 cells (15). Our results are in accordance with those in these in vitro studies. Certain components, such as caffeic acid esters and artepillin $\mathrm{C}$, of propolis, which is used as a traditional medicine with a long history in Eastern Europe and Brazil, have been reported to exert antimutagenic and anticarcinogenic effects (31-33). The findings in this study suggest that other components, like chrysin in propolis $(0.8 \mathrm{mmol}$ chrysin/100 $\mathrm{g}$ of Brazilian propolis) (34), may serve as cancer chemopreventive agents.

In conclusion, this study demonstrates for the first time that dietary administration of chrysin significantly inhibits the development of AOM-induced colonic ACF in rats. 
Although the exact mechanisms by which chrysin inhibits ACF development remain to be elucidated, it would appear that the modulation of colon tumorigenesis by chrysin in diet is associated with the alteration of cell proliferation activity and apoptosis.

\section{Acknowledgements}

This work was supported in part by a Grant-in-Aid for Cancer Research, for the Third-Term Comprehensive 10-Year Strategy for Cancer Control from the Ministry of Health, Labour and Welfare of Japan; a Grant-in-Aid (no. 15.2052) for Scientific Research from the Ministry of Education, Culture, Sports, Science and Technology of Japan; a grant (H2005-6) for the Project Research from the High-Technology Center of Kanazawa Medical University; and a grant (C2005-3) for Collaborative Research from Kanazawa Medical University.

\section{References}

1. Parkin DM, Bray F, Ferlay J and Pisani P: Global cancer statistics, 2002. CA Cancer J Clin 55: 74-108, 2005.

2. Havsteen B: Flavonoids, a class of natural products of high pharmacological potency. Biochem Pharmacol 32: 1141-1148, 1983.

3. Middleton EJ and Kandaswami C: Effects of flavonoids on immune and inflammatory cell functions. Biochem Pharmacol 43: 1167-1179, 1992.

4. Mora A, Paya M, Rios JL and Alcaraz MJ: Structure-activity relationships of polymethoxyflavones and other flavonoids as inhibitors of non-enzymic lipid peroxidation. Biochem Pharmacol 40: 793-797, 1990.

5. Tsyrlov IB, Mikhailenko VM and Gelboin HV: Isozyme- and species-specific susceptibility of cDNA-expressed CYP1A P-450s to different flavonoids. Biochim Biophys Acta 1205: 325-335, 1994.

6. Sanderson JT, Hordijk J, Denison MS, Springsteel MF, Nantz MH and van den Berg $\mathrm{M}$ : Induction and inhibition of aromatase (CYP19) activity by natural and synthetic flavonoid compounds in H295R human adrenocortical carcinoma cells. Toxicol Sci 82: 70-79, 2004.

7. Williams CA, Harborne JB, Newman M, Greenham J and Eagles J: Chrysin and other leaf exudate flavonoids in the genus Pelargonium. Phytochemistry 46: 1349-1353, 1997.

8. Rapta P, Misik V, Stasko A and Vrabel I: Redox intermediates of flavonoids and caffeic acid esters from propolis: an EPR spectroscopy and cyclic voltammetry study. Free Radic Biol Med 18: 901-908, 1995.

9. Liang YC, Tsai SH, Tsai DC, Lin-Shiau SY and Lin JK: Suppression of inducible cyclooxygenase and nitric oxide synthase through activation of peroxisome proliferator-activated receptor-gamma by flavonoids in mouse macrophages. FEBS Lett 496: 12-18, 2001.

10. Murakami A, Matsumoto K, Koshimizu K and Ohigashi H: Effects of selected food factors with chemopreventive properties on combined lipopolysaccharide- and interferon-gammainduced IkappaB degradation in RAW264.7 macrophages. Cancer Lett 195: 17-25, 2003.

11. Suzuki R, Kohno H, Murakami A, et al: Citrus nobiletin inhibits azoxymethane-induced large bowel carcinogenesis in rats. Biofactors 22: 111-114, 2004.

12. Kohno H, Suzuki R, Yasui Y, Hosokawa M, Miyashita K and Tanaka T: Pomegranate seed oil rich in conjugated linolenic acid suppresses chemically induced colon carcinogenesis in rats. Cancer Sci 95: 481-486, 2004.
13. Zhang T, Chen X, Qu L, Wu J, Cui R and Zhao Y: Chrysin and its phosphate ester inhibit cell proliferation and induce apoptosis in Hela cells. Bioorg Med Chem 12: 6097-6105, 2004.

14. Woo KJ, Jeong YJ, Park JW and Kwon TK: Chrysin-induced apoptosis is mediated through caspase activation and Akt inactivation in U937 leukemia cells. Biochem Biophys Res Commun 325: 1215-1222, 2004.

15. Wang W, VanAlstyne PC, Irons KA, Chen S, Stewart JW and Birt DF: Individual and interactive effects of apigenin analogs on $\mathrm{G} 2 / \mathrm{M}$ cell-cycle arrest in human colon carcinoma cell lines. Nutr Cancer 48: 106-114, 2004.

16. Weng MS, Ho YS and Lin JK: Chrysin induces G1 phase cell cycle arrest in C6 glioma cells through inducing p21Waf1/Cip1 expression: involvement of p38 mitogen-activated protein kinase. Biochem Pharmacol 69: 1815-1827, 2005.

17. Pretlow TP, Barrow BJ, Ashton WS, et al: Aberrant crypts: putative preneoplastic foci in human colonic mucosa. Cancer Res 51: 1564-1547, 1991.

18. Pretlow TP, O'Riordan MA, Somich GA, Amini SB and Pretlow TG: Aberrant crypts correlate with tumor incidence in F344 rats treated with azoxymethane and phytate. Carcinogenesis 13: 1509-1512, 1992.

19. Bird RP: Role of aberrant crypt foci in understanding the pathogenesis of colon cancer. Cancer Lett 93: 55-71, 1995.

20. Kohno H, Maeda M, Honjo S, et al: Prevention of colonic preneoplastic lesions by the $\beta$-cryptoxanthin and hesperidin rich powder prepared from Citrus Unshiu Marc. juice in male F344 rats. J Toxicol Pathol 12: 209-215, 1999.

21. Pereira MA: Prevention of colon cancer and modulation of aberrant crypt foci, cell proliferation, and apoptosis by retinoids and NSAIDs. Adv Exp Med Biol 470: 55-63, 1999.

22. Tanaka T, Kawabata K, Kakumoto M, et al: Citrus auraptene inhibits chemically induced colonic aberrant crypt foci in male F344 rats. Carcinogenesis 18: 2155-2161, 1997

23. Wyllie AH, Kerr JF and Currie AR: Cell death: the significance of apoptosis. Int Rev Cytol 68: 251-306, 1980.

24. McLellan EA, Medline A and Bird RP: Sequential analyses of the growth and morphological characteristics of aberrant crypt foci: putative preneoplastic lesions. Cancer Res. 51: 5270-5274, 1991

25. Walle T, Otake Y, Brubaker JA, Walle UK and Halushka PV: Disposition and metabolism of the flavonoid chrysin in normal volunteers. Br J Clin Pharmacol 51: 143-146, 2001.

26. Hertog MGL, Hollman PCH and van de Putte B: Content of potentially anticarcinogenic flavonoids of tea infusions, wines, and fruit juices. J Agric Food Chem 41: 1242-1246, 1993.

27. Hertog MG, Feskens EJ, Hollman PC, Katan MB and Kromhout D: Dietary antioxidant flavonoids and risk of coronary heart disease: The Zutphen Elderly Study. Lancet 342: 1007-1011, 1993.

28. Knekt P, Jarvinen R, Reunanen A and Maatela J: Flavonoid intake and coronary mortality in Finland: A cohort study. BMJ 312: 478-481, 1996.

29. Keli SO, Hertog MG, Feskens EJ and Kromhout D: Dietary flavonoids, antioxidant vitamins, and incidence of stroke: The Zutphen study. Arch Intern Med 156: 637-642, 1996.

30. Le Marchand L, Murphy SP, Hankin JH, Wilkens LR and Kolonel LN: Intake of flavonoids and lung cancer. J Natl Cancer Inst 92: 154-160, 2000.

31. Rao CV, Desai D, Kaul B, Amin S and Reddy BS: Effect of caffeic acid esters on carcinogen-induced mutagenicity and human colon adenocarcinoma cell growth. Chem Biol Interact 84: 277-290, 1992.

32. Frenkel K, Wei H, Bhimani R, et al: Inhibition of tumor promoter-mediated processes in mouse skin and bovine lens by caffeic acid phenethyl ester. Cancer Res 53: 1255-1261, 1993.

33. Kimoto $\mathrm{T}$, Arai S, Kohguchi M, et al: Apoptosis and suppression of tumor growth by artepillin $\mathrm{C}$ extracted from Brazilian propolis. Cancer Detect Prev 22: 506-515, 1998.

34. Shimizu K, Ashida H, Matsuura Y and Kanazawa K: Antioxidative bioavailability of artepillin $\mathrm{C}$ in Brazilian propolis. Arch Biochem Biophys 424: 181-188, 2004. 